\title{
ORAL SUBMUCOUS FIBROSIS;
}

COMPARISONOFEFFICACYBETWEENCLOBETASOLANDTRIAMCINOLONE APPLICATION IN ORAL SUBMUCOUS FIBROSIS PATIENTS WITH BURNING SENSATION

1. BDS. MSc.

Student of Oral Surgery Department,

Faculty of Dentistry \& Allied

Sciences, Isra University,

Hyderabad.

2. BDS, MDPH.

Associate Professor and Head

Department of Community and Preventive Dentistry,

Faculty of Dentistry \& Allied

Sciences, Isra University,

Hyderabad

3. BDS. F.C.P.S.,

Associate Professor

Department of Oral Surgery,

Faculty of Dentistry \& Allied

Sciences, Isra University,

Hyderabad

Correspondence Address:

Dr. Hassan Shahid.

Associate Professor and Head

Department of Community

and Preventive Dentistry,

Faculty of Dentistry \& Allied Sciences

Isra University, Hyderabad.

Hala road, P.O.Box 313, Hyderabad.

dr_hassanshahid@hotmail.com

Article received on:

11/10/2017

Accepted for publication:

20/04/2018

Received after proof reading:

00/00/2018

\section{Aisha Memon ${ }^{1}$, Hassan Shahid ${ }^{2}$, Salman Shafique ${ }^{3}$}

ABSTRACT... Objectives: To compare the efficacy of topical Triamcinolone $0.1 \%$ with Clobetasol $0.05 \%$ in the known cases of Oral Submucous Fibrosis presenting with burning sensations. Study Design: Cross sectional hospital based study. Setting: Department of Oral \& Maxillofacial Surgery, Isra Dental College, Isra University Hospital, Hyderabad. Period: Six months. Materials and Methods: A sample of 50 patients was selected through nonprobability purposive sampling according to inclusion and exclusion criteria. 50 patients with Oral Submucous Fibrosis were divided into two groups, Group A and Group B, each having 25 patients. The pain was measured by the visual analog scale on the scale of 1-10. Patients were divided into Groups ' $A$ ' (Triamcinolone $0.1 \%$ ) and ' $B$ ' (Clobetasol $0.05 \%)$. Patients were advised to use the gel twice a day for 3 weeks on the affected mucosal surfaces and were also advised to avoid swallowing for some minutes and not to drink or eat for at least 1 hour after the application of drug. Patients were recalled for follow up to record any improvements in burning sensations after the application of the drug. Results: It was seen that both topical drugs were beneficial in controlling the burning pain in Oral Submucous Fibrosis in the 3 weeks duration, however Clobetasol was better than Triamcinolone, as measured by more rapid control of pain by week 1 . Conclusion: It is concluded that the efficacy of both topical oral drugs were useful in diminishing pain and decreasing the burning sensations. However, Clobetasol has to some extent better effectiveness in reducing the burning sensation in patients suffering with Oral Submucous Fibrosis.

Key words: Oral Submucous Fibrosis, Burning, Triamcinolone, Clobetasol.

Article Citation: Memon A, Shahid H, Shafique S. Oral submucous fibrosis; comparison of efficacy between clobetasol and triamcinolone application in oral submucous fibrosis patients with burning sensation. Professional Med $\mathrm{J}$ 2018; 25(7):1005-1012. DOI:10.29309/TPMJ/18.4408

\section{INTRODUCTION}

Oral submucous fibrosis (OSF) a chronic disease of insidious onset with a prevalence rate of $3.2 \%$ in south East Asian countries. ${ }^{1}$ World estimates of betel nut consumption show a prevalence of $20 \%$ of population chewing areca nut. It is characterized by mouth opening difficulty. OSF carries a significant risk of oral cancers with the malignancy potential rate of $7.6 \% .^{2}$ OSF is a chronic progressive disorder; the patients are intolerant to spicy food. The rigidity of lip, tongue and palate occurs. The rigidity of oral parts causes limitation of tongue movement and mouth opening. The hallmark of OSF is pathological fibrosis of submucous tissue which affects most of the oral cavity, oro-pharynx and upper $1 / 3$ of esophagus. ${ }^{3}$
In Pakistan Oral Submucous Fibrosis is becoming somewhat common and most of the time not curability results in loss of normal functions of the patients in their routine life. In order to assess this impact of oral submucous fibrosis on patients this study is being carried out which will focus on the assessment result of oral disorders on the health and quality of life due to this debilitating disease. ${ }^{4-6}$

Chewing of areca nut is a proven agent for OSF. The areca nut is proved to be carcinogenic and areca nut chewing is one of the notorious causes. Currently, prevalence of areca nut chewing is as high as $27.06 \%$ which has been reported from Indore, India. A number of etiologic agents have been marked ranging from gene factors to auto- 
immune reactions; however one of the directly linked etiologic agent is the areca nut/betel nut use. ${ }^{7}$ Patients present with significant oral cavity complaints, such as mouth burning, oral discomfort and difficult chewing.

The disease is predominantly seen in Asian countries including India, Pakistan, Bangladesh, Srilanka, Taiwan and China, with a higher incidence recorded in second decade of life (73\%). The average age is recorded as 18 years. The male to female ratio is recorded as $1.5: 1 .{ }^{4}$

The onset of OSF is insidious and early symptoms are burning sensation in the mouth with blister formation and ulceration (97\%). In later stages of the disease, the patients present with limited mouth opening due to stiffening of oral mucosa leading to difficulty in eating, swallowing, speech, and maintenance of oral hygiene. ${ }^{4-8}$

The incidence of OSF is very high, and an effective medical and surgical treatment is yet lacking related to the problem, therefore it is advisable to diagnose the problem at an early stage. Public health awareness programs, interventional studies and a change in habits may bring goodness to society to overcome problems at the community level.

\section{OBJECTIVES}

To compare the efficacy of topical Triamcinolone $0.1 \%$ with Clobetasol $0.05 \%$ in the known cases of Oral Submucous Fibrosis presenting with burning sensations.

\section{Rationale}

Topical effects of Triamcinolone and Clobetasol on the burning sensation in OSF patients has been researched and observed individually and demonstrate a positive effect on the burning effects of OSF, however no study has been done in comparison to find out the efficacy of these two topical drugs as to which is more better. In Pakistan neither individually nor in comparison any studies have been performed. This study will in turn help to provide an effective locally administered topical agent for the management of burning, so that the patients suffering from Oral Submucous Fibrosis can at least maintain their regular diet and therefore may be prevented from secondary nutritional deficiencies.

\section{MATERIAL AND METHODS}

Our study is an observational study of the general population $\mathrm{N}=50$, out of which 30 were males and 20 were females respectively. Patients visiting the Dental OPD of Isra dental college, Isra University from $1^{\text {st }} J$ uly to $31^{\text {st }}$ December 2016 were recruited. Patients coming to the OPD of Isra Dental College are generally both from rural and urban areas as Hyderabad is a small city and adjoining cities don't have tertiary based hospitals in their localities. All patients presenting with Oral Submucous Fibrosis which was diagnosed clinically and were not on any treatment for OSF were included into this nonprobability purposive sampling study. There was no restriction on the age or gender of the patients and everyone who came with OSF were included into the study. Patients were included only if they were willing to quit the habit of chewing areca nut and other habits. Patients presenting with any medical condition that was coexisting with OSF were excluded from this study along with patients with other mucosal lesions like leukoplakia and malignant lesions. Patients with a history of allergies to corticosteroids were also excluded. All the data after compilation was analyzed and the results were put together. SPSS version 22 was used to analyze the data. The purpose was to compare the efficacy of topical Triamcinolone $0.1 \%$ with Clobetasol $0.05 \%$ in the known cases of Oral Submucous Fibrosis presenting with burning sensations. Written consent form was obtained from the patient and they were then categorized into two groups, Group A and Group B. Patients were distributed according to even and odd numbers, as there were 50 patients in this study, all patients who came at the odd number distribution like $1,3,5,7 \ldots$ Were in group $B$ (Clobetasol group) while all patients coming in the even number distribution were in group $A$ (triamcinolone).

- Group A: will be treated with topical Triamcinolone $0.1 \%$ (even)

- Group B: will be treated with topical Clobetasol 
propionate $0.05 \%$ (odd).

Group A: Patients were advised to use topical Triamcinolone $0.1 \%$ twice a day for 3 weeks over the affected areas. Patients were advised to avoid swallowing for some minutes and not to drink or eat for at least 1 hour after the application of drug

The patients were recalled on weekly basis to record any improvements in burning sensations after the application of the drug. ${ }^{9}$

Group B: Patient were advised to use Clobetasol gel $0.05 \%$ twice a day for 3 weeks on the affected mucosal surfaces. Patients were advised to avoid swallowing for some minutes and not to drink or eat for at least 1 hour after the application of drug. The patients were recalled on weekly basis to record any improvements in burning sensations after the application of the drug. ${ }^{10}$

Patients were recalled for follow up on Day3, Day5, week1, week2, and week3 postoperatively. Pain was assessed using VAS (visual analogue scale) of 1-10. Patients were asked to rate their pain on a scale of 1 to 10,1 being no pain and 10 being most severe, and their responses were recorded. ${ }^{11}$

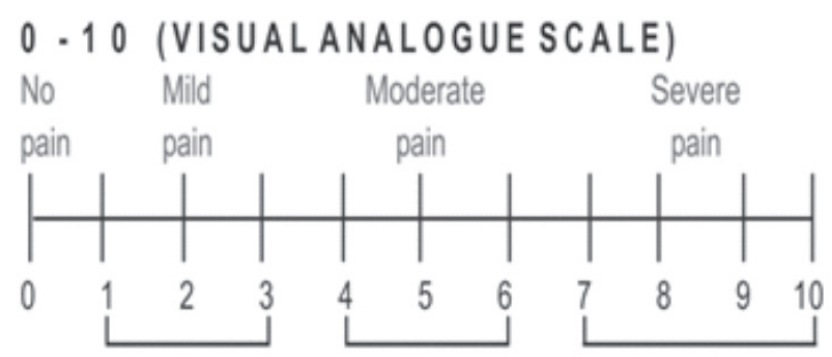

\section{GRADES ACCORDING TO VAS SCORE}

\section{RESULTS}

The present observational and hospital based study was conducted on patients suffering from Oral Submucous Fibrosis which were diagnosed clinically by a competent clinician. Age distribution of study subjects are shown in Table-l. Age ranged from as low as 11 till 65 years of age whereas age group of $30-39$ (34\%) was the most frequent age in the study population followed by $20-29$ (26\%) years and 50 - 59 (16\%) years of age respectively. The mean and standard deviation was $36.32 \pm 12.77$ respectively. Figure- 1 shows the gender distribution in which male population predominated over female. Frequency of male to female subjects was $30(60 \%)$ males and 20 $(40 \%)$ females respectively.

\begin{tabular}{|c|c|c|c|c|}
\hline $\begin{array}{c}\text { Age } \\
\text { Distribution }\end{array}$ & $\begin{array}{c}\text { Fre- } \\
\text { quency }\end{array}$ & $\%$ & Mean & S. D. \\
\hline Below 19 & 2 & $4 \%$ & \multirow{7}{*}{$\begin{array}{l}36 . \\
32\end{array}$} & \multirow{7}{*}{12.77} \\
\hline $20-29$ & 13 & $26 \%$ & & \\
\hline $30-39$ & 17 & $34 \%$ & & \\
\hline $40-49$ & 7 & $14 \%$ & & \\
\hline $50-59$ & 8 & $16 \%$ & & \\
\hline $60+$ & 3 & $6 \%$ & & \\
\hline Total & 50 & 100 & & \\
\hline
\end{tabular}

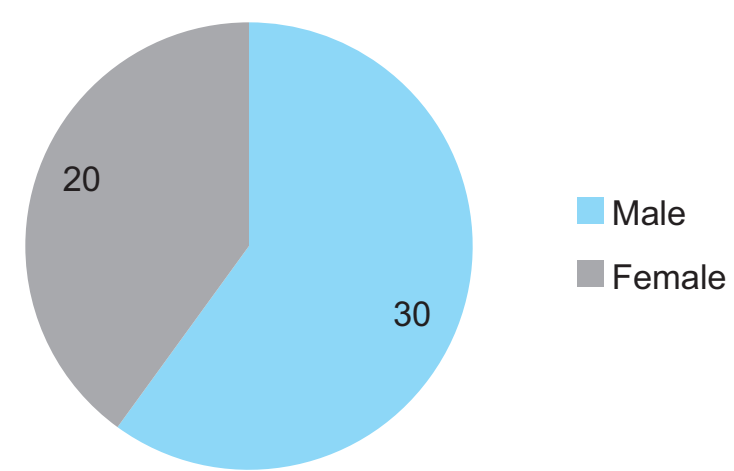

Figure-1. Frequency of gender distribution $(n=50)$

Table-Il shows the distribution of different habits that were present in the study population. Areca nut was the most used product in the study population with 29 (58\%) people using it. 13 (26\%) people were using more than one habit i.e. areca nut with pan or else guthka with smoking and pan etc.

\begin{tabular}{|c|c|c|}
\hline Habits & Frequency & Percent \% \\
\hline Guthka & 4 & $8 \%$ \\
\hline Areca Nut & 29 & $58 \%$ \\
\hline Pan & 4 & $8 \%$ \\
\hline More than One Habit & 13 & $26 \%$ \\
\hline Total & 50 & 100 \\
\hline
\end{tabular}

Table-III shows the gender distribution of study population in correlation with personal habits. It is seen that out of 29 people using areca nut 
12 were males and 17 were females. 12 males in respect to 1 female had more than one habit while all 4 males were guthka users. The $\chi^{2}$ was 12.68 and p-value .005 .

Table-IV shows the distribution of the study population in their respective groups of study i.e. 25 people in the Triamcinolone group and 25 people in the Clobetasol group. In the Triamcinolone group 18 were males and 7 were females. While in the Clobetasol group 12 were males and 13 were females respectively. The $\chi^{2}$ was 3.00 and p-value was .083 . The objective of the study was to compare the effects of the two drugs on patients suffering with burning sensation because of Oral Submucous Fibrosis; hence the results of the two drugs are as follows.

Table-V shows the severity of pain when applying the drugs in their respective groups. The pain was measured by the visual analog scale, on the scale of $1-10$.

\begin{tabular}{|c|c|c|c|c|c|c|c|c|c|}
\hline & \multicolumn{4}{|c|}{ Personal Habit } & \multirow{2}{*}{ Total } & & \multirow{2}{*}{ df } & \multirow{2}{*}{$p$-value } \\
\hline & & Guthka & Areca Nut & Pan & More than One Habit & & & & \\
\hline \multirow{2}{*}{ Gender } & Male & 4 & 12 & 2 & 12 & 30 & \multirow{3}{*}{12.68} & \multirow{3}{*}{3} & \multirow{3}{*}{.005} \\
\hline & Female & 0 & 17 & 2 & 1 & 20 & & & \\
\hline \multicolumn{2}{|c|}{ Total } & 4 & 29 & 4 & 13 & 50 & & & \\
\hline
\end{tabular}

\begin{tabular}{|c|c|c|c|c|c|c|c|}
\hline & & \multicolumn{2}{|c|}{ Group } & \multirow{2}{*}{ Total } & & \multirow{2}{*}{ df } & \multirow{2}{*}{ p-value } \\
\hline & & Triamcinolone & Clobetasol & & & & \\
\hline \multirow{2}{*}{ Gender } & Male & 18 & 12 & 30 & \multirow{3}{*}{3.00} & \multirow{3}{*}{1} & \multirow{3}{*}{.083} \\
\hline & Female & 7 & 13 & 20 & & & \\
\hline \multicolumn{2}{|c|}{ Total } & 25 & 25 & 50 & & & \\
\hline
\end{tabular}

\begin{tabular}{|c|c|c|c|c|c|c|c|}
\hline & & $\begin{array}{l}\text { Mild Pain } \\
(4-6)\end{array}$ & $\begin{array}{c}\text { Moderate Pain } \\
\quad(4-6)\end{array}$ & $\begin{array}{c}\text { Severe Pain } \\
(7-10)\end{array}$ & Total & $\chi^{2}$ & $\mathrm{p}$-value \\
\hline \multirow{2}{*}{ Pain day 3} & Triamcinolone & 0 & 1 & 24 & 25 & \multirow{3}{*}{0.355} & \multirow{3}{*}{0.552} \\
\hline & Clobetasol & 0 & 2 & 23 & 25 & & \\
\hline \multicolumn{2}{|c|}{ Total } & 0 & 3 & 47 & 50 & & \\
\hline \multirow{2}{*}{ Pain day 5} & Triamcinolone & 0 & 2 & 23 & 25 & \multirow{3}{*}{0.758} & \multirow{3}{*}{0.667} \\
\hline & Clobetasol & 0 & 4 & 21 & 25 & & \\
\hline \multicolumn{2}{|c|}{ Total } & 0 & 6 & 44 & 50 & & \\
\hline \multirow{2}{*}{ Pain week 1} & Triamcinolone & 0 & 6 & 19 & 25 & \multirow{3}{*}{0.397} & \multirow{3}{*}{0.529} \\
\hline & Clobetasol & 0 & 8 & 17 & 25 & & \\
\hline \multicolumn{2}{|c|}{ Total } & 0 & 14 & 36 & 50 & & \\
\hline \multirow{2}{*}{ Pain week 2} & Triamcinolone & 19 & 6 & 0 & 25 & \multirow{3}{*}{6.181} & \multirow{3}{*}{0.009} \\
\hline & Clobetasol & 25 & 0 & 0 & 25 & & \\
\hline \multicolumn{2}{|c|}{ Total } & 44 & 6 & 0 & 50 & & \\
\hline \multirow{2}{*}{ Pain week 3} & Triamcinolone & $\mathrm{O}$ & 25 & 0 & 25 & \multirow{3}{*}{28.125} & \multirow{3}{*}{0.001} \\
\hline & Clobetasol & 18 & 7 & 0 & 25 & & \\
\hline \multicolumn{2}{|c|}{ Total } & 18 & 32 & 0 & 50 & & \\
\hline \multicolumn{8}{|c|}{ Table-V. Severity of pain in relation to drugs $(n=50)$} \\
\hline
\end{tabular}

Pain day 3: In the Triamcinolone group 24 patients were in the severe pain scale and 1 patient was in the moderate pain scale. Whereas, In the Clobetasol 23 patients were in the severe pain scale and 2 patients were in the moderate pain scale. The $X^{2}$ was 0.355 and $p$-value 0.552 . The $P$-value is non-significant as both topical drugs takes longer time to show any effect.

Pain day 5: In the Triamcinolone group 23 patients were in the severe pain scale and 2 patients were in the moderate pain scale. Whereas, In the Clobetasol 21 patients were in the severe pain scale and 4 patients were in the moderate pain 
scale. The $\chi^{2}$ was 0.758 and $p$-value 0.667 . The $P$-value is non-significant. However Clobetasol shows a slight positive effect, as the number of patients have been slightly shifted from severe to moderate pain.

Pain Week 1: In the Triamcinolone group 19 patients were in the severe pain scale and 6 patients were in the moderate pain scale. Whereas, In the Clobetasol 17 patients were in the severe pain scale and 8 patients were in the moderate pain scale. The $\chi^{2}$ was 0.397 and $p$-value 0.529 . Although the P-value is non-significant, but there is a slight change in the severity of pain from severe to moderate with the application of both topical drugs, however Clobetasol showing more positive effect.

Pain Week 2: The distribution was from severe to moderate and mild, while Clobetasol had no patients in the severe pain group. The pain was measured by the visual analog scale on the scale of $1-10$. In the Triamcinolone group 6 patients were in the moderate pain scale and 19 patients were in the mild pain scale. Whereas, In the Clobetasol group, 0 patients were in the severe pain scale and 25 patients were in the mild pain scale. The $\chi^{2}$ was 6.818 and $p$-value 0.009 . The $P$-value is significant, as there is a significant change in the severity of pain after the application of both drugs; however Clobetasol seems to be more efficacious as none of the patient shown severe pain on week 2 .

Pain Week 3: In the Triamcinolone group 25 patients were in the moderate pain scale and 0 patients were in the mild pain scale. Whereas, In the Clobetasol group, 7 patients were in the moderate pain scale and 18 patients were in the mild pain scale. The $\chi^{2}$ was 28.125 and $p$-value 0.0001 . The $P$-value is highly significant on week 3 and there is a significant reduction in the burning pain from severe to mild and moderate, however Clobetasol proved to be better than Triamcinolone in the 3 weeks duration.

\section{DISCUSSION}

The present study is an original research in local population, which assessed the effects of two different topical drugs on the burning sensation of oral mucosa of Oral Submucous Fibrosis patients.

Topical forms of corticosteroids are preferred to systemic ones, because they are less harmful. On the other hand, corticosteroids are the first treatment of choice for autoimmune diseases. Synthetic Corticosteroids or steroids have been developed for their anti-inflammatory and immunomodulatory effects. In dentistry, corticosteroids are mainly useful in reducing post-surgical edema, which can cause postsurgical pain. Oral lichen planus, oral sub mucous fibrosis, pemphigus vulgaris, erythema multiforme, aphthous stomatitis and allergic reaction respond very well to topical or systemic corticosteroids. Contraindications of usage of corticosteroids include chronic condition such as diabetes mellitus, tuberculosis, osteoporosis, cataracts, viral infections etc. Long term usage of corticosteroids affects the central nervous system resulting in euphoria, sleeplessness, restlessness and psychosis. ${ }^{12-15}$

The present study used two forms of topical corticosteroids i.e. Clobetasol and Triamcinolone for the management of burning sensation in patients suffering from Oral sub mucous fibrosis. We took Oral Submucous Fibrosis as our choice because it has to some extent same points as lichen planus, pemphigus etc, and also its lymphocytic infiltration, autoimmune etiology, habits are somewhat similar. It was seen that both drugs had an effect in reducing the burning effect in the oral cavity. There were no such studies done in our region on the burning sensation related to OSF. Nevertheless, our results are consistent with studies outside Pakistan that have observed the effects of these drugs on the oral cavity. The male female ratio was seen to be $3: 2$. This is consistent to a study done in India by Amiya et al (2012) in which male predominance over females was seen. ${ }^{16}$ Males were dominated because it was noted that they used guthka and similar products more because of easy availability, whereas females being more conscious about their health and esthetics, possibly were more reluctant to use them. This could be one of the 
reasons responsible for a high male to female ratio. A study by Saimadhavi et al (2013) showed contrary results in which females' outnumbered males with the ratio of $1.25: 1 .{ }^{17}$ Areca nut is used frequently and in many forms these days that even all classes of people are using it even high class individuals. Present study shows that around $60 \%$ patients were areca nut users while $26 \%$ made more than one habit. This is consistent to a study done by Reddy, V., et al, (2011) in India who also reported that areca nut use was more as compared to pan, smoking or guthka. ${ }^{18}$ Reddy, $\mathrm{V}$., et al also reported that male patients were the majority users of areca nut which is in contrast to present study where females were in the majority areca nut users. ${ }^{18} \mathrm{~A}$ significant morbidity among Oral Submucous Fibrosis patients is the burning sensation that comes with it with its increase use. Initially all patients had severe pain but after three weeks follow-up it was seen that both topical drugs had significant results in reducing the pain score as measured on the Visual Analogue Scale. In present study all patients presented with severe pain and burning at the start which is in contrast to a study done by Reddy, V., et al, (2011) in India who reported that only $40 \%$ of the study group presented with severe pain while $49 \%$ were in moderate group and $11 \%$ were in mild group. ${ }^{18}$ This study showed that Clobetasol has to some extent better effect than Triamcinolone; this is consistent to a study done by Shahmoradi et al (2008) who also concluded that Clobetasol had a positive effect on the oral cavity. ${ }^{19}$ Triamcinolone is also said to reduce the burning sensation in the oral cavity, however our results showed an insignificant difference between Triamcinolone and Clobetasol. This is in contrast to a study done in Iran by Ahadian, $\mathrm{H}$ et al (2012), who reported that Triamcinolone was more efficacious in reducing pain in the oral cavity. ${ }^{20}$ Furthermore, as this study was not a longitudinal study it can be assumed that longer usage of these topical steroids may have had significant results but cumulative statistics show that Clobetasol is slightly better than Triamcinolone.

Another study reported in U.S. by Nur, F. et al (1994), concluded that Clobetasol used topically had a significant benefit in controlling the pain and burning sensation with minimal side effects. This is consistent with present study as Clobetasol was seen to be more effective when used topically in reducing the burning sensation of the oral cavity. ${ }^{21}$ Nur, F. et al used Clobetasol for their research to decrease the chances of side effects that occur by different potent topical steroids. The sample size was same and they observed that Clobetasol had a remarkable effect from day 7 . This is also consistent with our study as on day 7 we also observed significant reduction in burning sensation. ${ }^{21}$ Similar study done in Sweden by Rodstrom et al (1994), were also consistent with present study as they reported that Clobetasol in comparison with Triamcinolone was better. They recommended that both had undergone a successful strategy for topical corticosteroid therapy and can be used moderately until relief of symptoms is seen or more maintenance therapy. ${ }^{22}$

Devgan, K et al (2015) In India, concluded that Triamcinolone have significant response in early stages of Oral Submucous Fibrosis and also in achieving satisfactory mouth opening although no difference was seen in cheek flexibility. Nevertheless this is in contrast with present study as Clobetasol had a better effect than Triamcinolone. ${ }^{23}$ Even though both drugs showed a reduction in burning sensation on the oral mucosa, Clobetasol was slightly better. This is in consistent with a study done in Italy by Carbone, $\mathrm{M}$ et al (2008), who concluded that Clobetasol would appear to be a treatment of choice for patients with pain and discomfort. He also suggested that Clobetasol be used as a gel in hydroxyethyl cellulose form for better results. ${ }^{24}$ Naik, SM. et al (2012) in India concluded that Triamcinolone had no effect in reducing the burning sensation in the oral cavity in Oral Submucous Fibrosis patients; this is in contrast with present study as we observed that Triamcinolone did have an effect in reducing the burning sensation in patients. ${ }^{25}$ Another study done by Shahmoradi Z et al (2012) in Iran concluded that Clobetasol had a very low effect on treatment of burning sensation which is in contrast to present study where Clobetasol had a significant effect on reducing burning sensation. ${ }^{26}$ Age group is in contrast to a study done by Pinborg JJ, where 21-30 was the more frequent 
group. The reasons for increased consumption by youngsters include ease of availability at school canteens, confectionary shops and from friends. These products are cheap, colorfully packaged, often sweetened and conveniently carried thus increasing their attraction. In addition, there is no age restriction on sale. ${ }^{27}$

\section{CONCLUSION}

It is concluded that the efficacy of both topical oral drugs were useful in diminishing pain and decreasing the burning sensations. However, Clobetasol has to some extent better effectiveness in reducing the burning sensation in patients suffering with Oral Submucous Fibrosis.

\section{RECOMMENDATIONS}

Based upon the results of the present study, both topical corticosteroids, particularly Clobetasol $0.05 \%$ could be recommended for the management of burning in Oral Submucous Fibrosis patients. Further studies should be done to revalidate its efficacy with a larger sample size. Long term sustainable effects and relapse need to be studied.

\section{Copyright(C) 20 Apr, 2018.}

\section{REFERENCES}

1. Baharvand M, ShoalehSaadi N, Barakian R, Jalali Moghaddam $\mathrm{E}$. Taste alteration and impact on quality of life after head and neck radiotherapy. Journal of Oral Pathology \& Medicine. 2013;42(1):106-12.

2. Kerr A, Warnakulasuriya S, Mighell A, Dietrich T, Nasser M, Rimal J, et al. A systematic review of medical interventions for oral submucous fibrosis and future research opportunities. Oral diseases. 2011;17(s1):4257.

3. Khan S, Chatra L, Prashanth SK, Veena K, Rao PK. Pathogenesis of oral submucous fibrosis. Journal of cancer research and therapeutics. 2012;8(2):199.

4. Noor-ul-Wahab SA, Khan M, Khan S, Mehdi H, Sawani A. Frequency and clinical presentation of oral submucous fibrosis. Pakistan Journal of Medicine and Dentistry. 2014;3(04):48.

5. Naveed S. Prevalence of (osf) oral submucous fibrosis and risk factors in Karachi. practice.15:18.

6. Maqsood A, Aman N, Chaudhry MAG. Oral White Lesions: Presentation and Comparison of Oral
Submucous Fibrosis with Other Lesions. Journal of the College of Physicians and Surgeons--Pakistan: JCPSP. 2013;23(12):870-3.

7. Gupta M, Mhaske S, Ragavendra R. Oral submucous fibrosis-current concepts in etiopathogenesis. People's journal of Scientific Reasearch. 2008;1:39-44.

8. Rubab Z, Mughal AM, Baig S, Lucky MH, Azeem M. Relationship of human papilloma virus with trismus in chewable tobacco users. Pakistan Journal of Medicine and Dentistry. 2013;2(01):3-11.

9. Karthik P, Sande A, Ashwinirani S, Nayak A, Pawar R, Patil P. Comparison of Mouth Opening with Different Non-Surgical Treatment Modalities in Oral Submucous Fibrosis. American Journal of Drug Delivery and Therapeutics. 2015;2(3):072-7.

10. Varoni EM, Molteni A, Sardella A, Carrassi A, Di Candia D, Gigli F, et al. Pharmacokinetics study about topical clobetasol on oral mucosa. Journal of Oral Pathology \& Medicine. 2012;41(3):255-60.

11. Sumanth K, Ongole D, Rimal J. Efficacy of Dexamethasone Mucosal Patch for Oral Submucous Fibrosis (OSMF)-A Pilot Study. Int poster J dent oral med. 2010;12(2):Poster 484.

12. Mehdipour M, Zenouz AT. Role of corticosteroids in oral lesions: INTECH Open Access Publisher; 2012.

13. Srinivasan A, Shenai P, Laxmikanth Chatra VK, Rao PK. Topical Drugs for Pain Relief. Archives Medical Review Journal. 2015;24(1):92-104.

14. Masthan K, Babu NA, Dash KC, Elumalai M. Advanced diagnostic aids in oral cancer. Asian Pacific Journal of Cancer Prevention. 2012;13(8):3573-6.

15. Sankari SL, Masthan K, Babu NA, Bhattacharjee T, Elumalai M. Apoptosis in cancer-an update. Asian Pacific Journal of Cancer Prevention. 2012;13(10):48738.

16. Agrawal A, Chandel S, Singh N, Singhal A. Use of tobacco and oral sub mucous fibrosis in teenagers. J Dent Sci Res. 2012;3:1-4.

17. Saimadhavi N, Raju M, Reddy RS, Ramesh T, Tabassum DA, Ramya K. Impact of oral diseases on quality of life in subjects attending out-patient department of a dental hospital, India. Journal of Orofacial Sciences. 2013;5(1):27.

18. Reddy V, Wanjari P, Banda NR, Reddy P. Oral submucous fibrosis: Correlation of clinical grading to various habit factors. International journal of dental clinics. 2011;3(1). 
19. Shah $N$, Kumar $R$, Shah M. Immunological studies in oral submucous fibrosis. Indian journal of dental research: official publication of Indian Society for Dental Research. 1993;5(3):81-7.

20. Ahadian H, Karbassi MA, Vahidi A, Owlia F. Comparison of Two Corticosteroids Mouthwashes in Treatment of Symptomatic Oral Lichen Planus. Journal of Dentistry, Shiraz University of Medical Sciences. 2012;13(2):4953.

21. Lozada-Nur F, Miranda C, Maliksi R. Double-blind clinical trial of $0.05 \%$ clobetasol proprionate ointment in orabase and $\mathbf{0 . 0 5 \%}$ fluocinonide ointment in orabase in the treatment of patients with oral vesiculoerosive diseases. Oral Surgery, Oral Medicine, Oral Pathology. 1994;77(6):598-604.

22. Rödström P, Hakeberg M, Jontell M, Nordin P. Erosive oral lichen planus treated with clobetasol propionate and triamcinolone acetonide in Orabase: a doubleblind clinical trial. Journal of dermatological treatment. 1994;5(1):7-10.

23. Devgan K, Mistry P, Nagpal T. A prospective study of evaluation of methods to decrease the morbidity in oral submucous fibrosis. International Journal of Advances in Scientific Research. 2015;1(1):28-32.

24. Carbone M, Goss E, Carrozzo M, Castellano S, Conrotto D, Broccoletti R, et al. Systemic and topical corticosteroid treatment of oral lichen planus: a comparative study with long $\square$ term follow $\square$ up. Journal of Oral Pathology \& Medicine. 2003;32(6):323-9.

25. Naik SM, Appaji MK, Ravishankara S, Goutham M, Devi NP, Mushannavar AS, et al. Comparative Study of Intralesional Triamcinolone Acetonide and Hyaluronidase vs Placental Extract in 60 Cases of Oral Submucous Fibrosis.

26. Shahmoradi Z, Mokhtari F, Faghihi G, Adibi N. Comparing the efficacy of topical clobetasol $0.05 \%$ plus 5 FU $5 \%$ cream vs. topical clobetasol $0.05 \%$ alone in the treatment of vitiligo. Journal of Research in Medical Sciences. 2012;17.

27. Pindborg J, Zachariah J. Frequency of oral submucous fibrosis among 100 South Indians with oral cancer. Bulletin of the World Health Organization. 1965;32(5):750.

\section{6}

\section{The art of being wise is knowing}

\section{what to overlook.}

\section{- William James -}

\begin{tabular}{|c|c|c|c|}
\hline \multicolumn{4}{|c|}{ AUTHORSHIP AND CONTRIBUTION DECLARATION } \\
\hline Sr. \# & Author-s Full Name & Contribution to the paper & Author $=\mathbf{s}$ Signature \\
\hline 1 & Aisha Memon & Data collection, Data analysis & $\mathbb{N}_{2}$ \\
\hline 2 & Hassan Shahid & $\begin{array}{l}\text { Data interpretation, } \\
\text { References, formatting / proof } \\
\text { reading. } \\
\text { Literature search / review. }\end{array}$ & $\begin{array}{l}\text { namartalue } \\
\text { bel }\end{array}$ \\
\hline & & & \\
\hline
\end{tabular}

